\title{
Knowledge Translation Practices, Enablers, and Constraints: Bridging the Research-Practice Divide in Sport Management
}

\author{
Hebe Schaillée \\ Vrije Universiteit Brussel \\ Ramón Spaaij \\ Victoria University and University of Amsterdam \\ Ruth Jeanes \\ Monash University \\ Marc Theeboom \\ Vrije Universiteit Brussel
}

\begin{abstract}
Funding bodies seek to promote scientific research that has a social or economic impact beyond academia, including in sport management. Knowledge translation in sport management remains largely implicit and is yet to be fully understood. This study examines how knowledge translation in sport management can be conceptualized and fostered. The authors draw on a comparative analysis of coproduced research projects in Belgium and Australia to identify the strategic, cognitive, and logistic translation practices that researchers adopt, as well as enablers and constraints that affect knowledge translation. The findings show ways in which knowledge translation may be facilitated and supported, such as codesign, boundary spanning, adaptation of research products, and linkage and exchange activities. The findings reveal individual, organizational, and external constraints that need to be recognized and, where possible, managed.
\end{abstract}

Keywords: boundary spanning, coproduction, knowledge mobilization, research impact, sport for development, theory-practice divide

Knowledge translation has emerged as an important area of research activity to enhance the fit between research-based knowledge and its application in policy and practice (Greenhalgh \& Wieringa, 2011). National competitive research funding schemes increasingly demand that applicants demonstrate the contribution that their research makes to society. For example, the Australian Research Council (2018) states that "returns on investment in research will need to be demonstrated in terms of environmental, economic, and social impact," and it assesses and reports how investments in academic research translate to tangible national benefits. Academics are thus asked to focus not merely on academic impact, understood as the intellectual contribution to the field of study, but also to demonstrate wider research impact, which can be defined as the demonstrable contribution that research makes to society or the economy (Penfield, Baker, Scoble, \& Wykes, 2014). Consequently, researchers are often obligated to outline in their research grant proposals how research-based knowledge will be translated into beneficial outcomes, and their applications are assessed against this impact criterion.

Schaillée and Theeboom are with Research Unit Sport \& Society, Faculty of Physical Education and Physiotherapy, Vrije Universiteit Brussel, Brussels, Belgium. Spaaij is with the Institute for Health and Sport, Victoria University, Melbourne, Australia; and the Department of Sociology, University of Amsterdam, Amsterdam, The Netherlands. Jeanes is with the Faculty of Education, Monash University, Frankston, Australia. Address author correspondence to Hebe Schaillée at hebe.schaillee@vub.be.
Research impact can be facilitated or enhanced through deliberate planning and action (Beyer \& Trice, 1982; Canhoto, Quinton, Jackson, \& Dibb, 2016; Phipps, Cummings, Pepler, Craig, \& Cardinal, 2016). In sports research, systematic analysis of knowledge translation is still in its infancy (e.g., Mrazik, Bawani, \& Krol, 2011; Provvidenza et al., 2013). For several years, scholars and users have been pointing to the gap between research and practice in sport management (Holt et al., 2018; Martindale, Collins, \& Daubney, 2005). Users comprise nonacademic audiences including in particular policymakers, practitioners, and beneficiaries (i.e., sports participants). The knowledge base that could assist in bridging the gap between theory/research and practice in sport appears to lag behind. A recent study of research priorities among youth sports practitioners revealed that some priorities had already received extensive scientific attention, indicating that existing research had not been adequately transferred to relevant practitioners (Holt et al., 2018). The absence of systematic research on knowledge translation is also evident in sport management. Sport management scholars frequently collaborate with industry and community stakeholders, and are thus well positioned to contribute to policy and practice in this field. However, with some notable exceptions such as in the area of sport for development (e.g., Kay \& Dudfield, 2013; Welty Peachey \& Cohen, 2016), to date there appear to be relatively few deliberately designed pathways to research impact in sport management.

This study addresses the following question: How can knowledge translation be conceptualized and fostered in sport 
management? Through both the conceptual and empirical analysis of this question, we seek to contribute to identifying the different translation practices that researchers adopt, as well as the enablers and constraints that affect knowledge translation. The article is structured as follows. The next section defines and conceptualizes knowledge translation. We then discuss two applied research projects that will be analyzed in terms of their knowledge translation practices. By scrutinizing the knowledge translation practices in these projects, this study will contribute to the theoretical and practical understanding of how knowledge translation can be designed and implemented in sport management.

\section{Conceptualizing Knowledge Translation}

Conceptualizing knowledge translation requires not only a clear definition, but also consideration regarding the nature of the knowledge that is to be translated, and the practices by which this is done. We discuss each issue below.

\section{Defining Knowledge Translation}

Knowledge translation refers to the exchange, synthesis, and application of knowledge through a dynamic and iterative process of interactions between relevant stakeholders to accelerate the societal or economic impact of research (Straus, Tetroe, \& Graham, 2013; Sudsawad, 2007). In some research fields, most notably in health care, knowledge translation is an essential feature of the research process, as captured in "bench to bedside" and "campus to clinic" metaphors, and considered a key way to reduce the gap or time lag between research and practice (Morris, Wooding, \& Grant, 2011). Within sport management, integrated knowledge translation can accelerate the benefits of research-based knowledge in terms of strengthening policies, programs, and services, and improving their outcomes for individuals and communities. Multiple terms, such as knowledge utilization, knowledge transfer, and coproduction, are used to refer to the process of turning knowledge into action, even though they refer to different parts of this process (McKibbon et al., 2010). For example, utilization refers more narrowly to how policymakers and practitioners use research-based knowledge (Landry, Amara, \& Lamari, 2001), whereas knowledge translation primarily concerns the processes, practices, and contexts through which users engage with this knowledge.

Knowledge translation includes all steps between the creation of new knowledge and its application. It is frequently referred to in terms of multidirectional exchanges and interactions between researchers who create new knowledge and those who use it (Sudsawad, 2007). This process is iterative and dynamic, and its steps or phases can occur sequentially or out of phase depending on the context. Yet, the distinction between knowledge producers and users is somewhat problematic because integrated knowledge translation requires active collaboration between researchers and users throughout the research process (Kothari \& Wathen, 2013). In this process, research-based knowledge is coconstructed, circulated, and used among relevant parties, in conjunction with other types of knowledge. Kothari and Wathen (2013) argue that those involved in researcher-practitioner collaboration can create a new communal identity within their particular knowledge translation relationship, one that builds their capacity to value and understand each other's perspective and to share a worldview. The result of these translations is a new kind of knowledge: brokered knowledge (Meyer, 2010).
The interaction between research, policy, and practice involves potential for conflict or misalignment due in part to differences in values, goals, interests, epistemologies, forms of knowledge, resources, and timescales (Canhoto et al., 2016; Hammersley, 2013; Lottholz \& Kluczewska, 2017). For example, Green (2016) argues that, if anything, the different sides are too complementary, with "so little overlap between them that it is often difficult to team up." In a similar vein, Vaughan and Buss (1998) note that academics are socialized into different work cultures (e.g., ways of knowing, priorities, values, timescales) from policymakers or practitioners, which frequently results in various forms of misrecognition. Such differences can potentially be overcome through investment in linkage and exchange mechanisms between researchers and users in and beyond the life of a research project (Cherney \& McGee, 2010; Huberman, 1990; Landry et al., 2001). This can help build common ground among the respective interests of research partners (Clavier, Sénéchal, Vibert, \& Potvin, 2012). It can also lead to the cocreation of contextual knowledge. It is to this issue that we now turn.

\section{Forms of Knowledge in Translation}

An important question underpinning any knowledge translation framework is what type of knowledge is being translated. The critical knowledge translation literature challenges any narrow focus on the know-do gap by arguing that it constrains how we conceptualize and study the link between knowledge and practice (Carton \& Ungureanu, 2018; Greenhalgh \& Wieringa, 2011; Hammersley, 2013). Kitto, Sargeant, Reeves, and Silver (2012) argue that the knowledge translation literature wrongly privileges scientific knowledge over context-specific practical wisdom (phronesis). Any attempt to reduce knowledge translation to scientific knowledge or technical expertise, or to comprehend it exclusively in those terms, is misguided (Flyvbjerg, 2001; Hammersley, 2013). Practitioners rely heavily upon practical experience, professional judgment, and values. Their everyday practical knowledge is a crucial part of reflective practice, and as necessary and valuable as any other form of knowledge (Flyvbjerg, 2001). For this reason, some scholars argue for a broader focus in knowledge translation to include the contextspecific practical knowledge that underpins practice as well as the tacit knowledge that is built and shared among practitioners (Greenhalgh \& Wieringa, 2011). In knowledge translation practices, knowledge is assembled at this interface between academic and experiential knowledge within particular contexts (Clavier et al., 2012; Meyer, 2010). This process of knowledge tailoring is underpinned by the belief that generic academic knowledge is "seldom taken off the shelf and applied without some sort of vetting or tailoring to the context" (Graham et al., 2006, p. 20). In the next section, we outline our analytical framework that captures the different types of knowledge translation practices.

\section{Knowledge Translation: Cognitive, Strategic, and Logistic Practices}

The scientific literature on knowledge translation offers various theoretical approaches to understand what factors influence knowledge translation outcomes (e.g., Landry et al., 2001; Oborn, Barrett, \& Racko, 2013); models to describe the process of translating research into practice (e.g., Phipps et al., 2016); and frameworks that provide a structure for evaluating knowledge translation endeavors (e.g., Green \& Kreuter, 2005). For the 
purpose of this study, we synthesize and adapt some of the existing approaches and models to analyze how knowledge translation can be conceptualized and fostered in sport management. Figure 1 visualizes the analytical framework that guides our analysis. The components of the framework are discussed later.

Knowledge translation is an iterative process that involves changing relationships and transactions between the actors involved. As noted earlier, knowledge translation can create ways of reconciling different types of knowledge as the various interactions and negotiations between researchers and practitioners take place. Clavier et al.'s (2012) theory-based model of translation practices offers a valuable approach to studying these interactions. Their model separates key elements, or practices, for analyzing the relationships and interactions among actors as well as the contents of their transactions. This model was developed with a focus on the practices of actors mandated to support interactions and links between public health researchers and their community partners. In this article, we will adapt this model to the sport management context.

Clavier et al. (2012) distinguish three types of translation practices: cognitive, strategic, and logistic. Cognitive translation practices concern the meanings and content of the research. These practices focus on the establishment and implementation of a shared vision for the research and on the formulation of research questions that resonate with both researchers and practitioners. Strategic translation practices focus on raising and maintaining partners' interest in the research, through reconciling and potentially transforming diverging interests and priorities. Strategic translation involves three distinct practices (Clavier et al., 2012): Finally, logistic translation practices involve the handson tasks of coordination and organization. This set of practices primarily focuses on the logistics of communication and linkages with partners and users, such as e-mail or telephone communication, setting up meetings or committees, managing timetables, deadlines, budgets, and producing and disseminating accessible research outputs. While participants in Clavier et al.'s (2012) study downplayed the time and effort they invested in logistic practices of knowledge translation, the authors conclude that "strategic and cognitive translation and the interweaving of the practices associated with each require considerable logistical resources" (p. 800).

(a) Managing the research process: explaining the research process to partners, clarifying their expectations, and maintaining relationships between researchers and users (b) Raising and maintaining users' interest in the research: applying specific communication skills and techniques (e.g., circulation of notes and reports; attention to language and form in the presentation of research results) and using events to strengthen collaborative relationships

(c) Balancing power relations: facilitating the coproduction of knowledge among all partners, incorporating the voices of partners with fewer material and symbolic resources, and protecting users from excessive demands of research requirements.

\section{Enablers and Constraints of Knowledge Translation Practices}

The literature identifies individual, organizational, and external enablers and constraints associated with translation practices, which highlight the role of researchers and their interactions with prospective users. A first factor that enables or constrains knowledge translation is the intensity of linkage mechanisms between researchers and users (Landry et al., 2001; Lavis, Roberston, Woodside, McLeod, \& Abelson, 2003; OlmosPeñuela, Castro-Martínez, \& D'Este, 2014). Intensive contacts between researchers and users throughout the research process can enhance not only the uptake and practical application of research, but also lead to longer term collaboration that transcends the impact of a single study (Huberman, 1990; Phipps et al., 2016). Regular, longer term contacts between researchers and users can build trust and support joint learning and the shared exploration of resources (Canhoto et al., 2016). Specific linkage and exchange activities that can positively influence knowledge translation include informal personal contacts, participation in committees, boundary spanning, scholar practitioners, and exchange of personnel (Carton \& Ungureanu, 2018; Cherney \& McGee, 2010; Clavier et al., 2012; Green, 2016; Landry et al., 2001; Powell et al., 2013). Boundary spanners are considered particularly important in the knowledge translation literature. Boundary spanning involves bridging knowledge and facilitating interaction between the research context and user context (Powell et al., 2013; Safford, Sawyer, Kocher, Hiers, \& Cross, 2017).

A second enabler is the dissemination of research outputs to nonacademic audiences and, in particular, the adaptation of research products for the needs of users (Cherney \& McGee, 2010; Landry et al., 2001). Adaptation of research products to

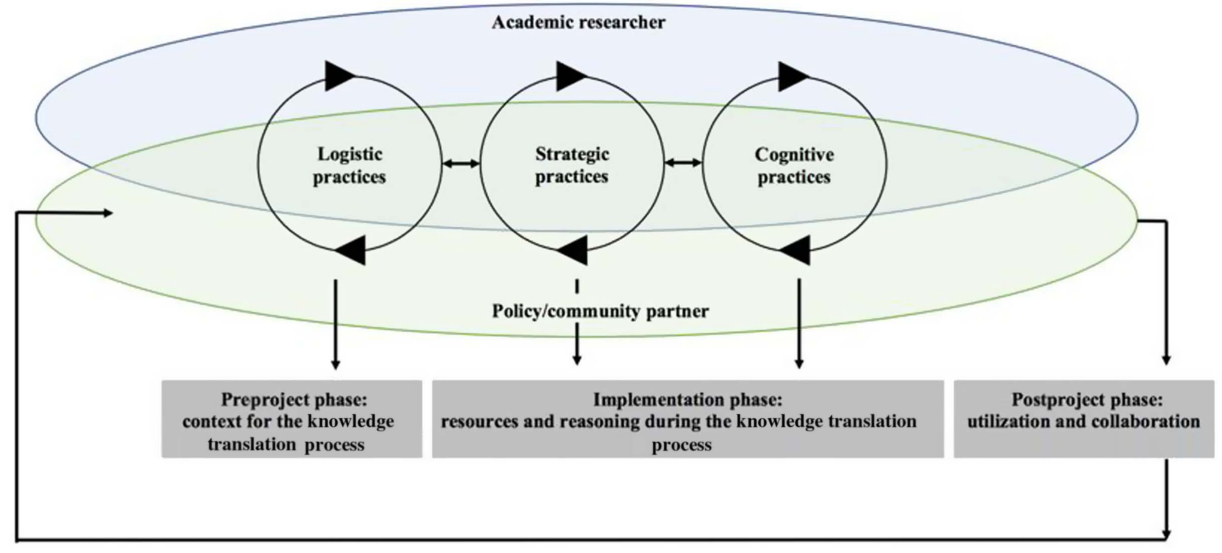

Figure 1 - Knowledge translation practices and contexts. 
users' needs includes focusing on readability of reports, operational recommendations, sensitivity to users' sensibilities, and the creation of appealing reports (Cherney \& McGee, 2010).

A third factor that influences knowledge translation is the source of research funding. Funding from external sources to universities is positively related to the utilization of knowledge in at least some social science disciplines, such as public administration (Landry, Lamari, \& Amara, 2003). This may be because researchers who rely on external sources of funds are arguably more outward looking and more sensitive to the needs of nonacademic users (Landry et al., 2001). External funding sources also often have in-built reporting and linkage mechanisms that can positively affect the translation and uptake of the research. However, as discussed later, the effect of external funding on knowledge translation is also highly dependent on the users' context and, in particular, on the extent to which funders, such as sports governing bodies, are looking for confirmation of their own beliefs and assumptions or are willing to adapt to new and critical insights from research.

These three variables can be considered as costs incurred by researchers in transacting with users (Landry et al., 2001). Cherney and McGee (2010) conclude that to achieve higher levels of research utilization, "researchers need to invest heavily in acquiring skills, expertise and the know-how to engage policy-makers and practitioners, in conjunction with efforts at customizing research that is tailored to end-users" (p. 156). Yet, knowledge translation requires dual accountability frameworks that involve both researchers and users (Safford et al., 2017). We consider users' organizational context as a fourth factor that influences knowledge translation. Specifically, the uptake of research appears to increase as users consider research pertinent, as research coincides with an existing target audience of users, as users attribute credibility to research, and as research reaches users at the right moment (Cherney \& McGee, 2010; Landry et al., 2001, 2003). Investment by researchers to make the users' context more receptive to research incurs further costs. However, this is a transactional process in which policymakers and practitioners have an important role and responsibility for creating an organizational context that is receptive to research translation and uptake (Beyer, 1997). For example, the user context may only support research that reasserts political assumptions regarding the social impact sports policies or programs are expected to have (e.g., Agergaard, 2018). In such cases, policymakers and practitioners use research symbolically to sustain and legitimate their existing views or political position (Beyer \& Trice, 1982). This raises the previously mentioned dilemma regarding what actually counts as legitimate knowledge and evidence.

Finally, a fifth factor concerns the organizational context within which researchers operate and, specifically, what is prioritized and valued within universities. For social science research in particular, historically there has been little value or reward placed within universities on knowledge translation activities, due to universities' performance-driven goals of academic publishing and attracting external research funding. In other words, the organizational context within which researchers work may not be receptive to knowledge translation practices (Spaaij, Schulenkorf, et al. 2018). The organizational context can misalign with the requirements of knowledge translation and research impact, which include a commitment to knowledge translation in the long term, beyond the life of a single study (Phipps et al., 2016; Safford et al., 2017).
In the following section, we discuss the methods used to examine the different components and factors associated with knowledge translation outlined previously.

\section{Methods}

The empirically grounded analysis that follows draws on empirical evidence and illustrative examples of knowledge translation practices, enablers, and constraints gleaned from two separate studies that were conducted independently by the authors. Our aim was to build theory on knowledge translation in sport management through bringing together and assessing researcher experiences and empirical evidence from the two studies within a single analysis. We used the research question to interrogate the data and findings of each study by placing them within a conceptual framework of knowledge translation. This framework centered on the conceptual model in Figure 1, with a particular focus on cognitive, strategic, and logistic translation practices.

\section{Study Selection}

The two studies were selected purposively for the rich information they would yield on knowledge translation processes. The first route to their selection was the researchers' familiarity with the cases (Thomas, 2011). The authors' intimate knowledge of the design, management, and implementation of the studies enabled indepth reflective analysis of knowledge translation practices. Both studies developed and embedded particular knowledge translation strategies and mechanisms into their design; yet, as will be shown, other practices emerged more serendipitously or, alternatively, failed to materialize. The selection of two cases allowed for comparative analysis of knowledge translation practices and the effect of enablers and constraints within the study contexts.

Table 1 outlines the main characteristics of the two studies. Both studies are applied research projects that used a mixed methods research design.

Study 1 aimed to examine the impact of community sport on personal development, health, and social cohesion. This study was commissioned by the Flemish Government Agency for Innovation and Entrepreneurship. It comprised a multidisciplinary collaboration involving 15 Flemish and four international researchers in conjunction with local community sports practices, policymakers, and umbrella organizations for primary sport structures and community sport. The project was designed to advance scientific understanding of the societal impact of community sport provision, but also to produce insights that are beneficial for community sports practitioners. Its practical applications were developed in conjunction with a regional nonprofit organization (i.e., subcontractor) that operates as an intermediary between local community sport and policymakers to inspire the latter to establish and improve community sport practices. The project involved built-in knowledge translation mechanisms designed to ensure research codesign and policy and community uptake (discussed later).

Study 2 aimed to identify how diversity is understood, experienced, and managed in junior sport in Australia, and to develop resources and guidelines that sports organizations can use in their decision making and practices around diversity. This project was funded by the Australian Research Council and conducted by four universities in partnership with the Victorian Health Promotion Foundation, Australian Football League, and Centre for Multicultural Youth. Similar to the first study, this research was applied in nature, aiming to translate research-based knowledge on diversity 
Table 1 Case Characteristics

\begin{tabular}{|c|c|c|}
\hline & Study 1 & Study 2 \\
\hline Aim & $\begin{array}{l}\text { Develop innovative strategies for promoting personal development, } \\
\text { health, and social cohesion through community sport }\end{array}$ & $\begin{array}{l}\text { Enhance the community sport sector's capability } \\
\text { to promote diverse and inclusive sports environments }\end{array}$ \\
\hline Location & Belgium & Australia \\
\hline Duration & 4 years $(2016-2019)$ & 4 years $(2014-2018)$ \\
\hline Funding & Flemish Government Agency for Innovation and Entrepreneurship & $\begin{array}{l}\text { Australian Research Council and Victorian Health } \\
\text { Promotion Foundation }\end{array}$ \\
\hline Methods & $\begin{array}{l}\text { Mixed methods comprising: } \\
\text { - } 319 \text { participatory observation hours } \\
\text { - } 59 \text { individual in-depth interviews } \\
\text { - } 9 \text { focus groups } \\
\text { - Content analysis } \\
\text { - Action research }\end{array}$ & $\begin{array}{l}\text { Mixed methods comprising: } \\
\text { - } 450 \text { surveys } \\
\text { - } 101 \text { interviews } \\
\text { - } 200 \text { observation hours } \\
\text { - Social network analysis } \\
\text { - Policy analysis }\end{array}$ \\
\hline Reference & Schaillée, Vyncke, Debognies, Sabbe, and Steenberghs (2017) & Spaaij, Farquharson, et al. (2018) \\
\hline
\end{tabular}

in junior sport into tangible outcomes for the community sport sector and other relevant stakeholders, including educational resources and community capacity building training. The project worked closely with a range of local sports clubs throughout the research process.

\section{Data Collection and Analysis}

For the purpose of this particular article, our analytical and empirical focus is the research translation processes associated with the studies, as opposed to the substantive findings of the studies themselves. We used and compared data on the different stages of the two research projects - from design to dissemination-to elicit insights into how knowledge translation practices took shape in the studies and the factors and conditions that enabled or constrained these practices. The data we used and analyzed for the purpose of this article were drawn from multiple sources: minutes of internal project team meetings; minutes and reports of external partner meetings; field notes on interactions between the research team and users during meetings and events (e.g., symposia, workshops, project launch); notes on and, where available, audio recordings of formal and informal conversations with research team members, partner investigators, and users; and products produced by the research teams (e.g., reports, media articles, websites, blogs, videos, infographics).

These data were managed and analyzed as follows. All notes, recordings, and products were stored on password-protected drives. We thematically analyzed the data using the themes from the theoretical framework (Figure 1), with a focus on cognitive, strategic, and logistic translation practices, and associated enablers and constraints. Data analysis focused on the identification of themes and clarification of patterns that cut across cases (Miles \& Huberman, 1994). The first stage of the data analysis process involved developing a robust understanding of the dynamics of knowledge translation in each particular study (Study 1 and Study 2). As noted, this process was aided by the selection of studies with which we were intimately familiar (i.e., studies we had designed and conducted ourselves), which enabled us to preserve context (Spaaij, Farquharson, et al., 2018). We discussed and reflected on the contextuality of the studies and their findings on several occasions during the analysis process to ensure that the findings remained sensitive to the context in which they were produced, and to identify relevant contextual factors. This included discussion of, for example, the conditions within which the studies were conducted, researcher-user interactions took place, and research outputs were produced and disseminated.

The second stage focused on the identification of cross-case patterns. Patterns from one study were compared systematically with the evidence from the other. We initially listed the similarities and differences between the pair of studies (Eisenhardt, 1989). This was followed by a closer examination of differences and, in particular, the context-specific enablers and constraints that shaped these differences. Finally, the evidence from each study and the cross-case patterns were compared with the conceptual framework (Figure 1) with the aim to provide new theoretical insight (Eisenhardt, 1989). In the next section, we discuss the findings elicited through these analytical procedures.

\section{Findings}

The two studies examined in this article exhibit a variety of interactions and behaviors that are indicative of the cognitive, strategic, and logistic translation practices outlined in the conceptual framework. Table 2 summarizes the main translation practices performed in the research projects. The practices provide insight into how researchers and their interactions with stakeholders and users affect the translation process. The practices will be related to enablers and constraints that emerged as salient from the cross-case analysis (see Table 3). In this section, we discuss these issues in relation to strategic, cognitive and logistic translation practices, respectively.

\section{Strategic Practices}

Strategic translation practices entail all interactions and behaviors that raise and maintain the interest and commitment of different actors involved in the research and that manage power relations between them. Below we discuss in detail the strategic practices outlined in Table 2.

Codesign. Codesign was a central principle of the projects' strategic translation practices. In Belgium, the researchers managed codesign through action research. The project established three practical interventions within which action research was used as an interactive inquiry process. Two approaches underpinned this research. The first approach, exemplary action research (Coenen, 1987), is characterized by advocacy. For example, in one of the 
Table 2 Comparison of Knowledge Translation Practices

\begin{tabular}{|c|c|c|c|}
\hline Category & Specific Practice & Study 1 & Study 2 \\
\hline \multirow[t]{4}{*}{ Strategic practices } & Codesign & $\begin{array}{l}\text { Cocreated research aims, questions, } \\
\text { products, and research methods }\end{array}$ & $\begin{array}{l}\text { Cocreated research aims, questions, } \\
\text { methodology, and products }\end{array}$ \\
\hline & $\begin{array}{l}\text { Events to build a communal } \\
\text { identity }\end{array}$ & $\begin{array}{l}\text { Joint dissemination of research results at } \\
\text { conferences and accessibility mechanisms }\end{array}$ & $\begin{array}{l}\text { Joint hosting of annual forum, community } \\
\text { capacity building and training activities, and } \\
\text { accessibility mechanisms }\end{array}$ \\
\hline & Dissemination platforms & $\begin{array}{l}\text { Research project website, newsletters, } \\
\text { professional and scientific publications, and } \\
\text { multimedia resources on partner's } \\
\text { knowledge database }\end{array}$ & $\begin{array}{l}\text { Multimedia resources posted on end-user } \\
\text { websites, conference and industry } \\
\text { presentations, media coverage, and } \\
\text { scientific publications }\end{array}$ \\
\hline & Adapting research products & Accessible products & Accessible products \\
\hline \multirow[t]{3}{*}{ Cognitive practices } & Linkage and exchange activities & $\begin{array}{l}\text { Practitioners as coapplicants and official } \\
\text { partner organizations } \\
\text { (Pre)kick-off meeting, workshops, } \\
\text { seminars, learning labs, annual meeting with } \\
\text { regional policy makers }\end{array}$ & $\begin{array}{l}\text { Practitioners as coapplicants and official } \\
\text { partner organizations, pilot study, scoping } \\
\text { meetings, workshops, annual forum with } \\
\text { policy makers, and practitioners }\end{array}$ \\
\hline & Assembling knowledge & No deliberate practices & $\begin{array}{l}\text { Consultations that bring together research } \\
\text { based, professional judgment, and practical } \\
\text { knowledge, pilot study }\end{array}$ \\
\hline & Evaluative tools & $\begin{array}{l}\text { Event evaluations and community } \\
\text { consultations }\end{array}$ & $\begin{array}{l}\text { Event evaluations and community } \\
\text { consultations }\end{array}$ \\
\hline \multirow[t]{3}{*}{ Logistic practices } & Boundary spanning & $\begin{array}{l}\text { Nonprofit organization that operates at the } \\
\text { interface between local community sports } \\
\text { practices and policymakers }\end{array}$ & $\begin{array}{l}\text { Partner organization representatives as } \\
\text { intermediaries between researchers and } \\
\text { users }\end{array}$ \\
\hline & Reconciling timescale problems & $\begin{array}{l}\text { Phased delivery and dissemination of } \\
\text { research outputs }\end{array}$ & $\begin{array}{l}\text { Phased delivery and dissemination of } \\
\text { research outputs }\end{array}$ \\
\hline & Policy outreach & $\begin{array}{l}\text { Policy advice to regional policymakers, } \\
\text { presentations to local/regional policymakers } \\
\text { and practitioner communities, practical } \\
\text { outputs as a way to reach a wide audience } \\
\text { and to stimulate policy uptake }\end{array}$ & $\begin{array}{l}\text { Policy advice to sports governing bodies, } \\
\text { presentations to policymakers and } \\
\text { practitioner communities, and media } \\
\text { coverage as a way to elicit policy uptake }\end{array}$ \\
\hline
\end{tabular}

Table 3 Enablers and Constraints of Knowledge Translation Practices: Cross-Case Patterns

\begin{tabular}{|c|c|c|}
\hline Context & Enabler & Constraint \\
\hline Individual & $\begin{array}{l}\text { Shared purpose and understanding among team members } \\
\text { - Regular interaction among researchers and users } \\
\text { - Team members who are open-minded about new ways of } \\
\text { producing and translating knowledge } \\
\text { - Coproduction of research } \\
\text { - Boundary spanners with the ability to navigate and bridge } \\
\text { research and user contexts }\end{array}$ & $\begin{array}{l}\text { Investment costs of knowledge translation incurred by } \\
\text { researchers and users } \\
\text { - Need for realistic expectations about challenges of } \\
\text { working together } \\
\text { - Boundary work as an additional responsibility of } \\
\text { researchers } \\
\text { - Privileging of scientific knowledge over context-specific } \\
\text { practical knowledge }\end{array}$ \\
\hline Organization & $\begin{array}{l}\text { - Structural embeddedness of partner organizations within } \\
\text { the project } \\
\text { - Organizational support for knowledge translation activities } \\
\text { in research institutions } \\
\text { - Long-term linkages between research and user contexts } \\
\text { beyond the life of a project } \\
\text { - Formal dual accountability arrangements }\end{array}$ & $\begin{array}{l}\text { - Academics and practitioners have different ways of } \\
\text { working } \\
\text { - Academics and practitioners work against different } \\
\text { timescales } \\
\text { - Users may support research only to reassert existing views } \\
\text { or political positions } \\
\text { - Conflicting demands on researcher's time and/or clash } \\
\text { with other organizational goals } \\
\text { - Low commitment to knowledge translation postproject } \\
\text { - Limited specialized education and training for researchers } \\
\text { in knowledge translation }\end{array}$ \\
\hline External & $\begin{array}{l}\text { Third parties can assist with the development of user } \\
\text { networks and linkages } \\
\text { - External funding support for knowledge translation } \\
\text { activities } \\
\text { - Access to existing user or third-party platforms for } \\
\text { research dissemination and communication }\end{array}$ & $\begin{array}{l}\text { - Scarcity of highly skilled boundary spanners } \\
\text { - Lack of identification, training, and retention of boundary } \\
\text { spanners }\end{array}$ \\
\hline
\end{tabular}


interventions, the action researcher developed a research strategy to improve knowledge with regard to the structural and political role of community sports practitioners within their respective communities. In the second approach, action research relies on its more common understanding characterized by joint action and joint responsibility (Van Beinum, 1998). In this second approach, action researchers took the questions and needs expressed by community members themselves as a point of departure and used intervention mapping (Bartholomew et al., 2016) as a protocol for developing their intervention. While both approaches varied with regard to the way power relations were managed during the first stage of the action research process, this type of research was considered vital for building and maintaining trust within the partnerships and linked to values of equality and reciprocity. In addition, three community sport labs (CSLs) were established to involve a broader group of users who were not directly involved in the research. In addition to engaging different user groups to create the necessary conditions for conducting the research, the CSLs served as a community of practice, bringing together a group of people who shared a common concern and passion for community sport and learned how to improve their practices through regular interaction (Wenger, 1998). Finally, the CSLs acted as locally embedded steering groups, where the knowledge translation products were developed, implemented, and tested. The involvement of the previously mentioned subcontractor enabled the practical and logistical organization of the CSLs, and its professional experience and networks facilitated the research team's access to key stakeholders and end users.

In contrast, the Australian project pursued codesign through a more formal arrangement in which all research and translational activities were developed in close collaboration with, and with formal approval from, the partner organizations and other users. This involved collaborative design of research objectives, questions, methods, outcomes, dissemination strategies, and research translation activities. Codesign enabled both the Belgian and Australian research teams to pay ongoing attention to the usability of the research for, and its accountability to, policymakers and practitioners, as well as to its uptake by end users such as local sports clubs and community sports practices.

Events to build a communal identity. Both research teams used both small and large events to tighten collaborative relationships among researchers and practitioners. In Belgium, the kick-off meeting not only provided researchers with vital insight into preexisting practical knowledge held by practitioners, but it also helped to identify ways to develop a common language and address potential communication difficulties (e.g., decoding theoretical knowledge) by emphasizing the parties' shared values of equality and reciprocity. The insights and recommendations that derived from events such as the kick-off meeting informed subsequent stages of the research. For instance, the joint dissemination of research results contributed to the recognition of practitioners and consequently allowed the Belgian researchers to strengthen their relationships with practitioners in the community sports practices. Yet, a difference was observed between community sports practitioners who were actively involved in the research and those who were not. The research team was able to develop more of a communal identity with the former owing to regular and intensive interactions throughout the research project.

A similar dynamic was observed in the Australian research, where research forums and community-based workshops acted as bonding rituals that tightened the relationships between the researchers and users. The research team and partner organizations were able to strengthen their communal identity through the joint establishment of the inaugural national Diversity and Inclusion in Sport Forum (2016), which was attended by over 150 policymakers, practitioners, and community members. This forum subsequently transformed into an annual event that brings together the various stakeholders around the shared commitment to enhancing diversity policy and practice in sport.

To manage power relations between the various actors and create equal participation opportunities, both projects made deliberate efforts to tailor their events to the needs, resources, and priorities of users, and to ensure their accessibility to a variety of community stakeholders. In the Australian project, events were free or heavily subsidized. For example, the national forums were able to charge $\$ 99$ registration fees due to sponsorship support from government agencies; in addition, free tickets were made available to those who struggled to afford the registration cost (approximately $10 \%$ of attendees, mainly volunteers from local sports clubs). Free workshops were held at two of the participating university campuses thanks to internal funding support. At the grassroots level, researchers traveled to various local sports clubs in urban and rural areas to deliver in-house presentations and workshops to club leaders and members. Similar initiatives were taken in the Belgian project, including free workshops on impact, cocreation, and monitoring and evaluation, in-house presentations to community sports practitioners. Research and translational activities were spread geographically to allow practitioner participation for those actors who were more likely to disengage due to time/ distance constraints.

Dissemination platforms. Researchers in both projects used multiple dissemination platforms to raise and maintain interest among a broad range of stakeholders, yet they did so in divergent ways. Belgian researchers mainly used one-way informative communication through the project website, newsletter, and publications in professional journals. These platforms afforded limited opportunities to foster in-depth interaction and dialogue with users regarding the content and meaning of the research. However, they enabled the researchers to disseminate research-based knowledge to a broader range of stakeholders, including end users, and to subsequently engage them in the research. Several new community-based organizations joined the project's "social user group" based on the information they received. Organizations that officially joined the social user group, which contained 18 community sports practices and 22 umbrella organizations, committed to reflect at least once a year with the researchers on several aspects related to the knowledge translation process. In this study, the use of informative dissemination platforms appeared to foster reflection in terms of content and meaning between researchers and practitioners in a rather indirect way. This illustrates the intertwinement between cognitive and strategic translation practices.

More interactive dissemination platforms, such as in-house workshops or social media, can be used to trigger collaborative reflection on the content and meaning of the research in a more direct way. The previously mentioned workshops delivered to local sports clubs in Australia are a case in point. The Australian research team was able to stimulate deep reflection and discussion with club leaders and volunteers using context-specific presentations and research summaries that were tailored specifically to the club in question. These workshops invariably led to long discussions among club members and researchers with regard to the meaning and implications of the research findings; how they related to practical knowledge; and what actions needed to be taken to address the issues discovered (e.g., racial discrimination). 
Adapting research products. In accordance with good practice (e.g., Vaughan \& Buss, 1998), the studies deliberately created accessible research products that were packaged in a practical way. In Australia, the researchers and partners cocreated a set of research outputs that targeted different audiences: a full report for those seeking an in-depth understanding of the research and its findings; a 15-page summary report for policymakers and practitioners; and a two-page infographic for community sports clubs and grassroots participants (e.g., coaches, volunteers, parents, young people). The reports were accompanied by a feature article in a leading newspaper, and a feature article with "practical tips" and a 10-min TEDx style video published on the website of the national platform Play by the Rules. End users praised the accessibility of these adapted products. For example, one policymaker commented that they provided "a lot of insight and evidence that has been made very accessible and useful, with real practical actions."

In the Belgian project, several nonacademic research outputs that target different audiences have been created. These include a practical handbook aimed at community sports practitioners, 10 publications in media outlets and professional journals geared toward end users; a two-page project flyer; a quick scan (i.e., a topic list to assess the current situation in a community sport practice); a training module for community sport coaches; and a symposium bringing together international experts and local practitioners. These adapted research outputs enabled not only engagement and uptake of the research by a wide range of users, but they also provided a context within which cognitive translation practices could take place and be disseminated. It is to such cognitive practices that we now turn.

\section{Cognitive Practices}

Cognitive translation practices entail all interactions and behaviors that help identify and circulate users' knowledge and needs in terms of the design, content, and meaning of the research (Clavier et al., 2012). In the following sections, we distinguish three sets of cognitive practices: linkage and exchange activities, assembling knowledge, and evaluative tools.

Linkage and exchange activities. Linkage and exchange activities were a central component of the cognitive practices within the two projects. In the Belgian project, linkage and exchange activities allowed researchers to gain insight into the opportunities and benefits that the research held for practitioners; to identify research questions that addressed the needs of community sport practices; and to give a range of practitioners access to external expertise (e.g., how to develop their own program theory). For instance, by discussing the study's overall conceptual framework during an exploratory meeting with key stakeholders, researchers were able to eliminate several dimensions of social inclusion that practitioners deemed irrelevant to the aims of community sport. This cognitive practice led to a shared vision for three "sport plus" aims of community sport that became the thematic foci within the project: personal development, health, and social cohesion. Through consultation with practitioners and initial data collection (e.g., participatory observations), researchers gained critical insight into the conceptualization and operationalization of the central themes, which directly informed the development of research questions for the subsequent action research in three community sports practices.

Cross-case analysis suggests that the formal involvement of nonacademic partners in the development of the projects was an important enabler of linkage and exchange activities. For example, the Australian project was funded through the Australian Research Council Linkage Projects scheme, which is designed specifically to promote research collaboration between universities, government, business, and community groups. Proposals for funding under the linkage projects scheme must include at least one partner organization, which must contribute financially to the project. In this particular project, the combined contributions from three formal partner organizations exceeded the total funding provided by the Australian Research Council. Linkage and exchange activities were built into the project design through the collaborative development of the research objectives and questions, as well as through formally defined roles and responsibilities. The partner investigators' commitment and contribution to the research was contractually agreed. This involved formal time commitment to the project and accountability for the performance of their roles and responsibilities. For example, based on their expertise and professional role, two partner investigators were tasked with facilitating the translation of the research findings into policy and practice, where the third partner investigator provided expert advice on the project design and supported the engagement of community-based sports clubs and other grassroots stakeholders within the project. The partner organizations were embedded throughout all stages of the research and were able to draw in other relevant stakeholders as needed. They also played a major role in identifying local clubs that were highly regarded for their good practices in relation to diversity and inclusion, which resulted in active engagement of these clubs within the research process. In addition, several local sports clubs and state sports associations were consulted regarding their priorities and needs in relation to the research topic. These consultations occurred during the previously mentioned events, but also through logistic practices such as e-mail, telephone, and face-to-face conversations with individual stakeholders.

In the Belgian study, the main nonacademic partners who were involved in all aspects of the research were representatives of the social user group, which comprised 18 community sport practices and 22 umbrella organizations. Representatives participated in a brainstorming session during the development phase of the research. In addition, these representatives and community sports practitioners were involved in the implementation phase through their active participation in the study or CSLs. As noted, formal collaboration with a nonprofit organization was established to facilitate the practical and logistical organization of all user group activities, which was led by a staff member at this organization and funded by the project at 0.5 fulltime equivalent. The representatives also played an important role in identifying community sports practices that were directly relevant to the thematic foci of the research.

Assembling knowledge. One purpose of the previously mentioned linkage and exchange activities is to assemble knowledge; that is, to bring together scientific and practical knowledge in novel ways (Meyer, 2010). In the Australian research, deliberate attempts were made to access and integrate the practical experience, professional judgment, and values of practitioners. These efforts were underpinned by recognition that grasping the context-specific and tacit knowledge that is built and shared among practitioners was critical to achieving the research objectives. To elicit this practical wisdom, years before the main research project began in earnest; the research team conducted a pilot study that comprised consultations with a variety of sports practitioners who dealt with diversity and inclusion issues on a daily basis. Through in-depth interviews and group discussions with these practitioners, the researchers sought to elicit their experiences, judgments, and values in relation to diversity in community sport. The outcomes of these 
consultations shaped the subsequent formulation of research objectives and questions. For example, the consultations revealed that clubs engaging with diversity experienced tensions between the promotion of diversity and inclusion on the one hand, and the focus on performance (i.e., winning) on the other hand. This became a thematic focus of the research and a key part of the research question. Subsequent workshops in both research projects further sought to bring together scientific and practical knowledge by combining, among others, research presentations with panel discussions involving local club leaders and volunteers.

Both projects experienced that assembling knowledge is not without tension or conflict. We encountered, for instance, a perception among policymakers that academic researchers typically struggle to translate research into practice. One policymaker involved in the Australian project stated that "Research needs to have tangible outcomes to influence policy change. We need tangibles, not just esoteric research. There is a place for that, but it's mostly meaningless to us." This comment is reflective of the idea that there are structural and cultural boundaries between researchers and end users (Safford et al., 2017), to the point where they may be seen to occupy different worlds (Green, 2016; Vaughan \& Buss, 1998).

This tension was evident in both projects, especially in relation to research dissemination. The Australian researchers preferred longer formats, such as a detailed report, that allowed for thick description, nuance, and complexity. In contrast, two partner organizations prioritized easily digestible summary reports and infographics, and questioned the need for more in-depth reporting. Through the boundary work performed by the community partner, a compromise was reached to have a multipronged reporting approach that addressed the different audiences (discussed further later in relation to logistic practices). In Belgium, a similar tension emerged in relation to the three $\mathrm{PhD}$ studies that were linked to the project. The output that really count for these junior researchers are academic publications, as opposed to nonacademic products.

Evaluative tools. Both projects used evaluative tools to gain access and insight into practitioners' knowledge and priorities. The Belgian project conducted practitioner evaluations with those attending its workshops on impact, cocreation, monitoring, and evaluation. Despite the low response rate, these online evaluations provided researchers with additional information related to the usefulness, applicability, and knowledge of practitioners with regard to previously mentioned topics and was subsequently used to further demystify aspects of the realist research approach when engaging with practitioners in the second research phase. The Australian project similarly conducted regular evaluations to identify end users' needs and priorities. Evaluation forms were disseminated at each workshop and forum organized by the project team. For example, evaluation results from the Diversity and Inclusion in Sport Forums we cohosted suggested that end users saw value in having an annual event to exchange knowledge and practices and that they were interested in creating an ongoing community of practice. These recommendations were taken up in subsequent stages of the research through the implementation of regular practitioner events (annual forum, workshops, and club presentations) and the mobilization of a community of practice involving local sports club staff and volunteers.

\section{Logistic Practices}

Logistic practices consist of strategies that enable knowledge translation during the different research phases including the design and development of a project, its implementation, and postproject. Logistic translation practices facilitate and support strategic and cognitive practices.

Boundary spanning. As noted earlier, boundary spanners can play a vital role in knowledge translation by managing and potentially bridging the boundaries between researchers and users. In the Belgian project, an intermediary organization was contracted to mitigate the challenges associated with knowledge coconstruction between researchers and practitioners. The boundary spanner was selected based on the organization's expertise, network, and capability to safeguard postproject sustainability. The boundary spanner was responsible for establishing and managing the CSLs and supporting the activities of the social user group. The boundary spanner also created platforms where practice-based tools could be developed and tested, such as training programs. Finally, the boundary spanner contributed to the effective communication of research-based knowledge to a wide range of end users.

Boundary spanning was also a key activity in the Australian project, but in a more informal manner. In this project, boundary spanning was primarily performed by two partner investigators in different ways. One boundary spanner acted primarily as a translator of practical knowledge and priorities ("what the sector needs/ wants") to inform the framing of the research and its accessibility and usefulness to practitioners. The second boundary spanner acted mainly as a mediator who tried to safeguard and bring together the various interests and values. This role involved navigating the previously mentioned tensions and conflicts between the researchers, partner organizations, and potential end users. An important enabler was the partner investigator's professional expertise and experience as a research manager, which enabled her to understand and communicate both scientific and practical interests and perspectives. Although her work prioritized grassroots community engagement and impact, she was also highly interested in engaging with research evidence in all its complexity. Her commitment to bridge the two worlds was fueled by the trust that the researchers and her organization had developed through previous collaborations. She regularly reinforced that the different actors involved had similar values, shared a common purpose, and that the researchers had previously proven that they deliver practical outcomes of direct benefit to the community sports sector, thereby easing potential concerns that the other partner organizations appeared to have. Both boundary spanners were also important in connecting the research team with other influential actors, such as sports governing bodies.

Boundary spanning activities were vitally important for knowledge translation, but also presented constraints. The effectiveness of boundary spanners was contingent upon individual characteristics that allowed them to achieve a balance of salience (i.e., relevance of the science to users' needs); credibility (i.e., perceived reliability and robustness of the research); and legitimacy of information (i.e., the perception that the research is sensitive to the values and phronesis of practitioners; McNie, 2007). One of these individual traits concern being sufficiently educated or experienced across the communities they aim to bring together. We found individuals with sufficient expertise to perform boundary spanning effectively to be in short supply. In the Belgian project, this resulted in the appointment of an individual with extensive practical experience but no academic experience. The specific profile of this boundary spanner affected his main tasks, which primarily involved communication and interaction across contexts. This person's input in terms of translating knowledge and mediating between researchers and practitioners remained limited. 
As a consequence, boundary spanning activities became an additional responsibility for the researchers, despite their lack of experience in the nonacademic context and their dissimilarities from the users in terms of education and technical knowledge (Roux, Rogers, Biggs, Ashton, \& Sergeant, 2006; Safford et al., 2017). This shift in responsibilities hindered the process of building mutual trust and recognition between researchers and users.

Reconciling timescale problems. In both projects, we encountered a familiar tension concerning timescales (Green, 2016): research takes time, yet our partners and end users wanted quick outcomes. Through the collective identification of research requirements and expected outcomes in the preliminary stages of the project, we were able to reconcile this timescale problem by devising a phased delivery model. Outputs were produced and communicated progressively at different stages of the project. In the Australian project, outputs developed during the early stages involved a project flyer, a media article, a short video presentation, a workshop summary published on the Sport for Development Platform (www.sportanddev.org), and an academic journal article based on the pilot study. These products were intended to generate interest in the project and to explain the research to partners and end users. As the research progressed, the project team released project updates and presented preliminary results at practitioner workshops and symposia, in conjunction with academic conference presentations and an academic journal article. The latter stages of the project included the release of a set of research reports, articles, media release, and a video (as noted previously). In the Belgian project, outputs developed in the early stages included a project flyer, professional publications, a six-monthly newsletter, a quick scan for community sport practices, and a project website and online platform for sharing all research outputs. Similar to the Australian project, the previously mentioned products were used to generate interest and active involvement among users to develop further research products to the benefit of a wide range of users.

Policy outreach. Policy outreach can contribute to knowledge translation by providing specific mechanisms for the uptake of research by policymakers. One of the major drivers for developing the Belgian study was the lack of regional policy on community sport. Metaphorically speaking, there appeared to be a lack of common community sports vocabulary (i.e., conceptual clarity) and grammar (i.e., the scientific principles underpinning how community sport can contribute to social inclusion). The project developed a policy outreach strategy that provided opportunities for researchers to interact directly with policymakers in the areas of sport, welfare, and youth. The underlying assumption of this outreach strategy was that research results are more likely to be used if there are regular interactions and relationships of trust with decision makers throughout the design and implementation of the study, which will enhance the credibility of the research (Landry et al., 2001, 2003). In the Belgian project, this mainly involved invited briefings for cabinet members and senior civil servants in different government departments (i.e., youth, welfare, and sport). These briefings enhanced policymakers' awareness and recognition of the research and led to various exchanges in which they sought research-based advice and input from the research team.

\section{Discussion}

The empirical findings operationalize the strategic, cognitive, and logistic translation practices that sport management researchers may develop and engage in. For each type of practice, we found different interactions and behaviors that shaped the translation process. In addition, the findings identify enablers and constraints that affect knowledge translation practices. Our findings directly inform and provide empirical evidence for current issues and debates in the knowledge translation literature.

First, several strategic, cognitive, and logistic translation practices identified in this study enabled the process of creating research-based knowledge and products that met the practical needs of users, such as codesign, boundary spanning, evaluative tools, and linkage and exchange activities. A major factor that influences effectiveness in translating knowledge is the development of accessible and usable, coproduced outputs that can subsequently assume boundary-spanning roles of their own (Safford et al., 2017). The quick scan and infographics produced in the projects are clear examples of this: they are accessible and userfriendly for practitioners, and practical enough to be updated or rebuilt for future use even in the absence of the original designer.

Our findings further highlight the importance of sustained academic-practitioner linkages and boundary spanners as mechanisms for bridging the perceived gap between research and practice and for creating new, context-specific knowledge (Powell et al., 2013; Safford et al., 2017). Specifically, the findings confirm that strategic and logistic translation practices that stimulate and embed interactions between coproducing parties from the very outset likely to have a positive effect on knowledge translation (Canhoto et al., 2016; Phipps et al., 2016; Powell et al., 2013). The formal involvement and commitment of nonacademic partners in the research had significant benefits, such as building a shared purpose and understanding, and maintaining users' interest in the research. In the projects examined here, boundary spanners were core members of one of both worlds (i.e., that of policy and practice), and only those in the Australian project were "legitimate members" of both research and user communities, while remaining peripheral to the academic world. Their efforts to move knowledge around and create connections between researchers and their audiences (Meyer, 2010) contributed to some level of dual accountability between researchers and users, and helped to ensure that boundary negotiation was a balanced and dynamic process (Safford et al., 2017). The challenges encountered in the Belgian project, where the boundary spanner was a full participant of only one of the served communities (i.e., practitioners), lend empirical evidence to Safford et al.'s (2017) call for the identification, training, and retention of knowledge translators who possess a suite of professional skills and individual traits that are still rare in academic circles.

Beyond individual factors that enable or constrain the effectiveness of the linkage and boundary spanning practices, it is important to consider the organizational factors that affect these practices. The idea of dual accountability is based on the view of knowledge translation as a transactional process in which both researchers and users have an important role and responsibility for fostering organizational contexts that are receptive to research translation (Beyer, 1997). Throughout this article, we have shown how the investments by researchers to make the users' context more receptive to research incur costs. Within academic institutions, the benefits of knowledge translation do not necessarily outweigh the costs. Despite the increasing focus in academia on research impact, individual researchers face universities' performance-driven goals of academic publishing and attracting external research funding. Depending on its source (i.e., national competitive grants schemes, sports governing bodies, philanthropy), this 
external funding can itself involve direct links with practitioners and policymakers.

The organizational context within which sport management researchers operate may not be receptive to knowledge translation practices (Spaaij, Schulenkorf, et al., 2018). The Australian research team encountered organizational pressures that restricted knowledge translation practices to the life of the project, such as short-term contracts, reduced workload hours upon formal project completion, and universities' prioritization of the pursuit of external funding for future research over knowledge translation. In Belgium, researchers experienced the pressure of having to translate their research findings (as an explicit project objective) and pursuing postdoctoral funding opportunities, while continuing their $(\mathrm{PhD})$ research and publishing from it. This pressure can affect the selection of specific action research approaches, such as exemplary action research (Coenen, 1987), in an attempt to make this inherently open-ended, messy, and long-term type of research more manageable and less open-ended. These organizational pressures can misalign with the requirements of knowledge translation and research impact, which include the maintenance of postproject linkages and fostering a commitment to knowledge translation over the long term (Phipps et al., 2016; Safford et al., 2017). Such pressures can also affect researchers' capacity to engage in regular interaction with users beyond the funding cycle. This is problematic because evidence shows that the regularity and intensity of such contacts correlates with the extent to which mutual trust is built, mutual learning and context-specific applications are achieved, and long-term collaboration that transcends the impact of a single study can be nurtured (Canhoto et al., 2016; Huberman, 1990; Phipps et al., 2016).

\section{Conclusion}

The purpose of this study is to examine how knowledge translation can be conceptualized and fostered in sport management. Our findings indicate various strategic, cognitive, and logistic translation practices that researchers can and do adopt, as well as ways in which knowledge translation may be facilitated and supported. Yet, we also found individual, organizational, and external constraints of knowledge translation that need to be recognized and, where possible, managed.

While this study is the first to systematically investigate knowledge translation practices in sport management, we recognize that the research presented in this article provides no more than a starting point for further research. First, it is important to note that empirical data are drawn from applied research that was designed with the purpose of informing policy and practice. We expect that at least some of the translation practices do not apply to basic research focused on producing new knowledge without any direct nonacademic application. Second, we acknowledge that the two projects do not provide an exemplar approach that does justice to all dimensions of existing knowledge translation frameworks. We have engaged with the three translation practices, and specific interactions and behaviors therein, to different degrees in each study context. Within each of the projects, we have been limited as to how fully we could adopt best-practice principles in knowledge translation. The research in Belgium, for example, experienced challenges regarding boundary spanning. Similarly, in Australia, funding constraints and organizational pressures placed on researchers limited some elements of knowledge translation, especially with regard to postproject translation practices. The data presented here thus need to be engaged critically, with particular attention to constraints and enablers that need to be acknowledged to realize knowledge translation objectives and outcomes. The analytical framework and empirical evidence presented in this article can encourage researchers to develop greater awareness of what knowledge translation in sport management requires, as well as strategies to navigate individual, organizational, and external constraints.

The findings of this study have implications for future research on knowledge translation in sport management. We have focused specifically on knowledge translation as a vital link between knowledge production and research impact. Clavier et al.'s (2012) model of translation practices enabled us to explore how knowledge translation is operationalized and implemented at the interface between researchers and practitioners. Further research is needed to better understand to what extent and how different actors endorse and contribute to translation practices to produce contextually applicable interventions. Such research and interventions could draw on the cocreating knowledge translation framework (Powell et al., 2013) to trace the different steps involved in the emergence of context-specific knowledge that can be used practically to achieve outcomes for end users of sport management services or programs. This would help to address the criticism that knowledge translation often fails to incorporate appropriate "methods whereby the end users of interventions or innovations might critically reflect on contextual related factors that might influence the embedding of an innovation within a context of practice" (Powell et al., 2013, p. 10). It would also contribute to broadening the focus in knowledge translation to include the practical and tacit knowledge of practitioners and end users (Greenhalgh \& Wieringa, 2011). Therein lays an important mechanism for bringing together theory and practice in sport management.

Finally, we recommend that future research investigate more holistically pathways to research impact in sport management. This study has focused on the translation process rather than on research outcomes and impacts that flow from it. Further research is required to discover how research-based knowledge is actually used, and with what impact on users. We envisage two fruitful avenues for research in this regard. First, research in this area can draw on the research utilization literature (Amara, Ouimet, \& Landry, 2004; Cherney \& McGee, 2010; Landry et al., 2003) to ascertain the extent and nature of instrumental, conceptual, and symbolic utilization of research in sport management practice. Second, by building on the latest advances in research impact methodologies (e.g., Phipps et al., 2016), researchers can map the specific research impact pathways in sport management. These strategies are especially pertinent at a time when there are growing pressures on researchers to achieve social and economic impact. They can contribute to the development of robust approaches to impact that would benefit sport management practice.

\section{Acknowledgments}

This article is part of the SBO-IWT project "CATCH" (Community sport for AT-risk youth: innovative strategies for promoting personal development, health and social CoHesion), carried out by the research group Sport and Society (Vrije Universiteit Brussel), the Department of Family Medicine and Primary Health Care, and the Department of Social Work and Social Pedagogy (Ghent University). This research project is subsidized by the Flemish Government Agency for Innovation and Entrepreneurship. The Australian research was supported by the Australian Research Council Linkage Projects scheme in partnership with VicHealth, the Centre for Multicultural Youth and the Australian Football League (grant number 
LP130100366). We thank co-investigators Karen Farquharson, Sean Gorman, Dean Lusher and Jonathan Magee for their contributions to this project.

\section{References}

Agergaard, S. (2018). Rethinking sport and integration: Developing a transnational perspective on migrants and descendants in sports. London, UK: Routledge.

Amara, N., Ouimet, M., \& Landry, R. (2004). New evidence of instrumental, conceptual, and symbolic utilization of university research in government agencies. Science Communication, 26, 75-106. doi:10.1177/1075547004267491

Australian Research Council. (2018). Research impact principles and framework. Retrieved from http://www.arc.gov.au/research-impactprinciples-and-framework

Bartholomew, L.K., Markham, C.M., Ruiter, R.A.C., Fernàndez, M.E., Kok, G., \& Parcel, G.S. (Eds.). (2016). Planning health promotion programs: An intervention mapping approach (4th ed.). Hoboken, NJ: Wiley.

Beyer, J.M. (1997). Research utilization: Bridging a cultural gap between communities. Journal of Management Inquiry, 6(1), 17-22. doi: $10.1177 / 105649269761004$

Beyer, J.M., \& Trice, H.M. (1982). The utilization process: A conceptual framework and synthesis of empirical findings. Administrative Science Quarterly, 27(4), 591-622. doi:10.2307/2392533

Canhoto, A.I., Quinton, S., Jackson, P., \& Dibb, S. (2016). The coproduction of value in digital, university-industry R\&D collaborative projects. Industrial Marketing Management, 56, 86-96. doi:10.1016/j.indmarman.2016.03.010

Carton, G., \& Ungureanu, P. (2018). Bridging the research-practice divide: A study of scholar-practitioners' multiple role management strategies and knowledge spillovers across roles. Journal of Management Inquiry, 27(4), 436-453. doi:10.1177/1056492617696890

Cherney, A., \& McGee, T.R. (2010). Utilization of social science research: A pilot study among Australian sociologists and criminologists. Journal of Sociology, 47(2), 144-162. doi:10.1177/ 1440783310386831

Clavier, C., Sénéchal, Y., Vibert, S., \& Potvin, L. (2012). A theory-based model of translation practices in public health participatory research. Sociology of Health \& Illness, 34(5), 791-805. PubMed ID: 21929647 doi:10.1111/j.1467-9566.2011.01408.x

Coenen, H. (Ed.). (1987). Handelingsonderzoek als exemplarisch leren. Een bijdrage aan de fundering van de methodologie van handelingsonderzoek [Action research as exemplary learning: A contribution to the foundation of action research]. Groningen, the Netherlands: Konstapel.

Eisenhardt, K. (1989). Building theories from case study research. Academy of Management Review, 14(4), 532-550. doi:10.5465/ amr.1989.4308385

Flyvbjerg, B. (2001). Making social science matter: Why social inquiry fails and how it can succeed again. Cambridge, UK: Cambridge University Press.

Graham, I.D., Logan, J., Harrison, M.B., Straus, S.E., Tetroe, J., Caswell, W., \& Robinson, N. (2006). Lost in knowledge translation: Time for a map? Journal of Continuing Education in the Health Professions, 26, 13-24. PubMed ID: 16557505 doi:10.1002/chp.47

Green, D. (2016). Academics and NGOs can work together in partnership but must do so earlier and with genuine knowledge exchange. LSE Impact Blog. Retrieved from http://blogs.lse.ac.uk/impactof socialsciences/2016/10/19/why-is-it-still-so-hard-for-academics-andngos-to-work-together/
Green, L.W., \& Kreuter, M.W. (2005). Health program planning: An educational and ecological approach. New York, NY: McGraw-Hill.

Greenhalgh, T., \& Wieringa, S. (2011). Is it time to drop the "knowledge translation" metaphor? A critical literature review. Journal of the Royal Society of Medicine, 104(12), 501-509. PubMed ID: 22179293 doi:10.1258/jrsm.2011.110285

Hammersley, M. (2013). The myth of research-based policy and practice. London, UK: Sage.

Holt, N.L., Pankow, K., Tamminen, K.A., Strachan, L., MacDonald, D.J., Fraser-Thomas, J., . . . Camiré, M. (2018). A qualitative study of research priorities among representatives of Canadian provincial sport organizations. Psychology of Sport \& Exercise, 36, 8-16. doi:10.1016/j.psychsport.2018.01.002

Huberman, M. (1990). Linkage between researchers and practitioners: A qualitative study. American Educational Research Journal, 27(2), 363-391. doi:10.3102/00028312027002363

Kay, T., \& Dudfield, O. (2013). The Commonwealth guide to advancing development through sport. London, UK: Commonwealth Secretariat.

Kitto, S.C, Sargeant, J., Reeves, S., \& Silver, I. (2012). Towards a sociology of knowledge translation: the importance of being disinterested in knowledge translation. Advances in Health Sciences Education, 17(2), 289-299.

Kothari, A., \& Wathen, C.N. (2013). A critical second look at integrated knowledge translation. Health Policy, 109(2), 187-191.

Landry, R., Amara, N., \& Lamari, M. (2001). Climbing the ladder of research utilization: Evidence from social science research. Science Communication, 22(4), 396-422. doi:10.1177/10755470010220 04003

Landry, R., Lamari, M., \& Amara, N. (2003). Extent and determinants of utilization of university research in public administration. Public Administration Review, 63(2), 192-205. doi:10.1111/1540-6210. 00279.

Lavis, J., Roberston, D., Woodside, J., McLeod, C., \& Abelson, J. (2003). How can research organisations more effectively transfer research knowledge to decision makers? The Milbank Quarterly, 81(2), 221-248. PubMed ID: 12841049 doi:10.1111/1468-0009.t01-100052

Lottholz, P., \& Kluczewska, K. (2017). Ever wondered why practitioners treat researchers like a nuisance? The challenges of accessing expert knowledge. Field Research Method Lab at LSE, Retrieved from http://blogs.lse.ac.uk/fieldresearch/2017/10/19/why-practitioner-treatresearchers-like-a-nuisance/

Martindale, R.J., Collins, D., \& Daubney, J. (2005). Talent development: A guide for practice and research within sport. Quest, 57, 353-375. doi:10.1080/00336297.2005.10491862

McKibbon, K.A., Lokker, C., Wilczynski, N.L., Ciliska, D., Dobbins, M., Davis, D.A., . . Straus, S.E. (2010). A cross-sectional study of the number and frequency of terms used to refer to knowledge translation in a body of health literature in 2006: A Tower of Babel? Implementation Science, 5, 16. PubMed ID: 21080976 doi:10. 1186/1748-5908-5-16

McNie, E. (2007). Reconciling the supply of scientific information with user demands: An analysis of the problem and review of the literature. Environmental Science \& Policy, 10(1), 17-38. doi:10.1016/j.envsci. 2006.10.004

Meyer, M. (2010). The rise of the knowledge broker. Science Communication, 32(1), 118-127. doi:10.1177/1075547009359797

Miles, M.B., \& Huberman, A.M. (1994). Qualitative data analysis: An expanded sourcebook. Thousand Oaks, CA: Sage.

Morris, Z.S., Wooding, S, \& Grant, J. (2011). The answer is 17 years, what is the question: Understanding time lags in translational research. 
Journal of the Royal Society of Medicine, 104(12), 510-520. PubMed ID: 22179294 doi:10.1258/jrsm.2011.110180

Mrazik, M., Bawani, F., \& Krol, A. (2011). Sport-related concussions: Knowledge translation among minor hockey coaches. Clinical Journal of Sports Medicine, 21, 315-319. doi:10.1097/JSM. 0b013e31821e2b78

Oborn, E., Barrett, M., \& Racko, G. (2013). Knowledge translation in healthcare: Incorporating theories of learning and knowledge from the management literature. Journal of Health Organization and Management, 27(4), 412-431. PubMed ID: 24003630 doi:10. 1108/JHOM-01-2012-0004

Olmos-Peñuela, J., Castro-Martínez, E., \& D’Este, P. (2014). Knowledge transfer activities in social sciences and humanities: Explaining the interactions of research groups with non-academic agents. Research Policy, 43(4), 696-706. doi:10.1016/j.respol.2013.12.004

Penfield, T., Baker, M.J., Scoble, R., \& Wykes, M.C. (2014). Assessment, evaluations, and definitions of research impact: A review. Research Evaluation, 23(1), 21-32. doi:10.1093/reseval/rvt021

Phipps, D., Cummings, J., Pepler, D., Craig, W., \& Cardinal, S. (2016). The co-produced pathway to impact describes knowledge mobilization processes. Journal of Community Engagement and Scholarship, 9(1), 31-40.

Powell, K., Kitson, A., Hoon, E., Newbury, J., Wilson, A., \& Belby, J. (2013). A study protocol for applying the co-creating knowledge translation framework to a population health study. Implementation Science, 8, 98. PubMed ID: 23984982 doi:10.1186/1748-5908-8-98

Provvidenza, C., Engebretsen, L., Tator, C., Kissick, J., McCrory, P., Sills, A., \& Johnston, K. (2013). From consensus to action: Knowledge transfer, education and influencing policy on sports concussion. British Journal of Sports Medicine, 47(5), 332-338. PubMed ID: 23349319 doi:10.1136/bjsports-2012-092099

Roux, D., Rogers, K., Biggs, H., Ashton, P., \& Sergeant, A. (2006). Bridging the science-management divide: Moving from unidirectional knowledge transfer to knowledge interfacing and sharing. Ecology and Society, 11(1), 4. doi:10.5751/ES-01643-110104
Safford, H.D., Sawyer, S.C., Kocher, S.D., Hiers, J.K., \& Cross, M. (2017). Linking knowledge to action: The role of boundary spanners in translating ecology. Translational Ecology, 15(10), $560-568$.

Schaillée, H., Vyncke, V., Debognies, P., Sabbe, S., \& Steenberghs, E. (2017). Buurtsport, een onvoorwaardelijk aanbod: Een springplank voor sociale inclusie. Vlaams Tijdschrift voor Sportbeheer, 259, 108-113.

Spaaij, R., Farquharson, K., Gorman, S., Jeanes, R., Lusher, L., Guerra, C., . . Ablett, E. (2018). Participation versus performance: Managing (dis)ability, gender and cultural diversity in junior sport. Melbourne, Australia: Centre for Multicultural Youth.

Spaaij, R., Schulenkorf, N., Jeanes, R., \& Oxford, S. (2018). Participatory research in sport-for-development: Complexities, experiences and (missed) opportunities. Sport Management Review, 21(1), 25-37. doi:10.1016/j.smr.2017.05.003

Straus, S., Tetroe, J., \& Graham, I.D. (Eds.). (2013). Knowledge translation in health care: Moving from evidence to practice. London, UK: Wiley.

Sudsawad, P. (2007). Knowledge translation: Introduction to models, strategies, and measures. Austin, TX: Southwest Educational Development Laboratory, National Center for the Dissemination of Disability Research.

Thomas, G. (2011). A typology for the case study in social science following a review of definition, discourse, and structure. Qualitative Inquiry, 17(6), 511-521. doi:10.1177/1077800411409884

Van Beinum, H. (1998). On the practice of action research. Concepts and Transformation, 3(1-2), 1-29. doi:10.1075/cat.3.1-2.02bei

Vaughan, R.J., \& Buss, T.F. (1998). Communicating social science research to policymakers. London, UK: Sage.

Welty Peachey, J., \& Cohen, A. (2016). Research partnerships in sport for development and peace: Challenges, barriers, and strategies. Journal of Sport Management, 30, 282-297. doi:10.1123/jsm.2014-0288

Wenger, E. (1998). Communities of practice: Learning, meaning, and identity. Cambridge, UK: Cambridge University Press. 